\title{
Severe COVID-19: NLRP3 Inflammasome Dysregulated
}

\author{
Daan F. van den Berg and Anje A. te Velde* \\ Amsterdam UMC, Academic Medical Center, Tytgat Institute for Liver and Intestinal Research, Amsterdam Gastroenterology, \\ Endocrinology and Metabolism, Amsterdam, Netherlands
}

SARS-CoV-2 might directly activate NLRP3 inflammasome resulting in an endogenous adjuvant activity necessary to mount a proper adaptive immune response against the virus. Heterogeneous response of COVID-19 patients could be attributed to differences in not being able to properly downregulate NLRP3 inflammasome activation. This relates to the fitness of the immune system of the individual challenged by the virus. Patients with a reduced immune fitness can demonstrate a dysregulated NLRP3 inflammasome activity resulting in severe COVID-19 with tissue damage and a cytokine storm. We sketch the outlines of five possible scenarios for COVID-19 in medical practice and provide potential treatment options targeting dysregulated endogenous adjuvant activity in severe COVID-19 patients.

Keywords: COVID-19, NLRP3 inflammasome, therapy, endogenous adjuvant activity, HMGB1

\section{OPEN ACCESS}

Edited by:

Alexis M. Kalergis,

Pontificia Universidad Católica de

Chile, Chile

Reviewed by:

Julie McAuley,

The University of Melbourne, Australia

Fayyaz S. Sutterwala,

University of lowa, United States

${ }^{*}$ Correspondence:

Anje A. te Velde a.a.tevelde@amsterdamumc.nl

Specialty section: This article was submitted to Viral Immunology, a section of the journa

Frontiers in Immunology

Received: 13 May 2020

Accepted: 15 June 2020

Published: 26 June 2020

Citation:

van den Berg DF and te Velde $A A$ (2020) Severe COVID-19: NLRP3

Inflammasome Dysregulated.

Front. Immunol. 11:1580

doi: 10.3389/fimmu.2020.01580

\section{IMMUNOPATHOPHYSIOLOGY OF COVID-19}

In one of the first analyses of patient characteristics of SARS-CoV-2 infection in Wuhan, China resulting in COVID-19, it was described that the virus affects largely adult age groups. In most patients there is a relative mild course of the infection. However, in $15.7 \%$ of affected patients the disease progresses into a severe disease with the need for hospitalization and admission into the ICU (1). Clinically, two phases of immune reaction against the virus can be identified (2). The first phase is the non-severe phase where a specific adaptive immune response is mounted that eliminates the virus and prevents disease progression to a more severe second stage. We will demonstrate from an immunological perspective that it is much more complex and that the body's response to a viral challenge depends on the immune fitness of the person challenged by the viral exposure. The behavior, adaptiveness and responsiveness will determine the intensity, adequacy and magnitude of the response as well as the speed of recovery. These immune fitness parameters can be used to define healthy or deviating behavior of the immune system (3). If the systemic resilience of a person that depends on regulatory subsystems and functional reserves of organs declines, the risks of morbidity and mortality increase (4).

The main question is why most patients show resilience and induce a proper virus eliminating immune response with resolution of the inflammation and what goes wrong in patients that advance to the severe state with tissue damage and an uncontrolled cytokine release, also specified as a cytokine storm.

After the first exposure to a virus, the detection of viral components by the immune system via a number of different receptors on and inside immune cells retinoic acid-inducible gene-I (RIGI)-like receptors (RLRs), Toll-like receptors (TLRs) and NOD-like receptors (NLRs) and cyclic GMP-AMP synthase (cGAS) activates intracellular signaling cascades, leads to the secretion of type I IFNs and pro-inflammatory cytokines and chemokines (5). Next to generating an innate antiviral response these intracellular signaling cascades also induce expression of co-stimulatory 
molecules such as CD40, CD80, and CD86 on antigen presenting cells important for initiation of an adaptive immune response. This necessary additional endogenous adjuvant activity is provided by pyroptotic cell death regulated by Nod-like receptor family, pyrin domain-containing 3 (NLRP3) inflammasome activation. These multiprotein complexes form in the cytosol and drive caspase- 1 cleavage and the secretion of the proinflammatory cytokines IL-1 $\beta$ and IL-18 and other damageassociated molecular patterns (DAMPs) (6). This stimulation of antigen presentation to benefit the induction of an adaptive immune response comes with a cost, because these danger signals give rise to toxicity and are the cause of a rise in body temperature and therefore need to be tightly controlled (7). If not properly monitored, if there is a reduced immune fitness, the consequences can be disastrous with neutrophils infiltrating in tissues, activated macrophages and skewed differentiation of $\mathrm{T}$ cells (Th17) all producing pro-inflammatory cytokines resulting in extensive tissue damage.

In the case of the coronavirus SARS-CoV, the endogenous adjuvant activity is caused by the direct activation of NLRP3 by a viral protein, named viroporin protein $3 \mathrm{a}$ (8). This viral protein is also present on the genome of SARS-CoV-2 suggesting that SARS-CoV-2 can also directly activate NLRP3 (9). One could ask what the survival/reproduction advantage of inducing NLRP3-mediated pyroptotic cell death would be for the virus, considering the deleterious consequences, including the activation of the immune reaction against the virus and possible death of the host. In contrast to the pyroptotic cell death in human, protein 3a has been described to have a pro-apoptotic function in the original host of the virus: bats (10). Because apoptosis does not, in distinction to pyroptosis, result in an immune reaction, in bats there is dampened immune response when NLRP3 is induced, limiting inflammation and stimulating asymptomatic carriage of the virus (11). So, the direct activation of NLRP3 resulting in pyroptosis could be an unintended sideeffect in humans. Given this situation, how can we as humans cope with this activation of NLRP 3 by SARS-CoV-2? It is of great clinical relevance to get an answer to this question, because then we might be able to find new markers that predict an outcome and find possible targets for therapeutic intervention that might reduce morbidity and mortality in severe COVID-19. What do we know of the ability to inhibit NLRP3 in patients that seem to be severely affected by SARS-CoV-2?

\section{SCENARIOS OF COVID-19 IMMUNE RESPONSE}

Based on the necessity to tightly regulate NLRP3 and its link to immune fitness there are five possible scenarios to outline the course of the SARS-CoV-2 infection in an individual (Figure 1). In the first scenario, after exposure to low viral load or enough non-specific defense mechanisms the innate immune response will do the job, without the necessity to raise an adaptive immune response. In this scenario there is lysis and phagocytosis by NK cells and macrophages, enough to clear all infected cells. The inflammatory activation of these cells is low and does not pass the threshold needed to activate NLRP3. In some cases it can nonetheless be activated coinciding with weak to average symptoms but not followed up by an adaptive response. In the second scenario there is NLRP3 activation that is strongly downregulated after the initial co-stimulation necessary for APC activation followed by a sufficient adaptive response and production of antibodies against the virus. In the third scenario there is some systemic effect resulting in clinical symptoms like fever and sickness behavior (12) because of the cytokines released during NLRP3 activation that is subsequently downregulated followed by a sufficient adaptive response and antibody production. In the fourth scenario a sustained NLRP3dependent inflammatory response results in severe clinical symptoms, necrosis, DAMP release and severe inflammation of the lungs. During a period of severe illness the patient is eventually able to mount an adaptive response with antibody production and recovers. In the fifth scenario the innate response is not able to clear the infection, resulting in an NLRP3 activation that is useless because the patient is unable to mount an adaptive response leading to viral clearance (13). In people that have a reduced capacity to mount a protective immune response it is possible that the virus will propagate and massive destruction of affected tissues will occur. This will lead to more DAMPs and a vicious circle of NLRP3 activation will finally result in death.

In all of our scenarios there is a central role for NLRP3 inflammasome regulation. Most literature is focused on the hyper activation of the NLRP3 inflammasome and the detrimental effect of the release of endogenous danger signals on the host. As already stated, the inflammation needs a tight control to be able to restore homeostasis after a challenge of the immune system. The downregulation of the NLRP3 inflammasome can be regulated in different ways, by post-translational modification of the NLRP3 inflammasome or by different NLRP3-interacting regulators. The post-translational modification of NLRP3 inflammasome can be mediated by ubiquitination or phosphorylation $(14,15)$. NLRP3interacting regulators Pyrin-only proteins (POPs) and CARDonly proteins (COPs) function in the downregulation of the inflammation. Expression of some of the POPs is upregulated by NF- $\kappa \mathrm{B}$ and IL- $1 \beta$ resulting in a feedback loop to prevent excessive NLRP3 activation (16). The COPs bind caspase-1 preventing autoactivation and limiting NLRP3 inflammasome activation (17).

The DAMPs released after NLRP3 inflammasome activation have a dual function. In a normal immune reaction they induce the necessary co-stimulatory activation of the APC, but they also play a role in resolution and tissue regeneration. Only in case of a hyperactivation of the NLRP3 inflammasome DAMPs are released in high concentrations and result in pyroptosis, High mobility group box 1 (HMGB1) release, activation of macrophages, neutrophil infiltration and reduced apoptosis, excessive cytokine production (IL-1 $\beta$, IL-2, IL-6, IL-17, TNF- $\alpha$, G-CSF, GM-CSF, IFN- $\gamma$, CXCL10, CCL2, and CCL3, cytokine storm) and fibrosis (Figure 2) (18-22). Not only does it explain the diversity of the symptoms of the patients, but it might also explain heterogeneity in the affected patients. Male PBMC were found to express significantly higher mRNA levels of NLRP3 pathway-related genes NLRP3, ASC (PYCARD), CASP1, CASP5, 


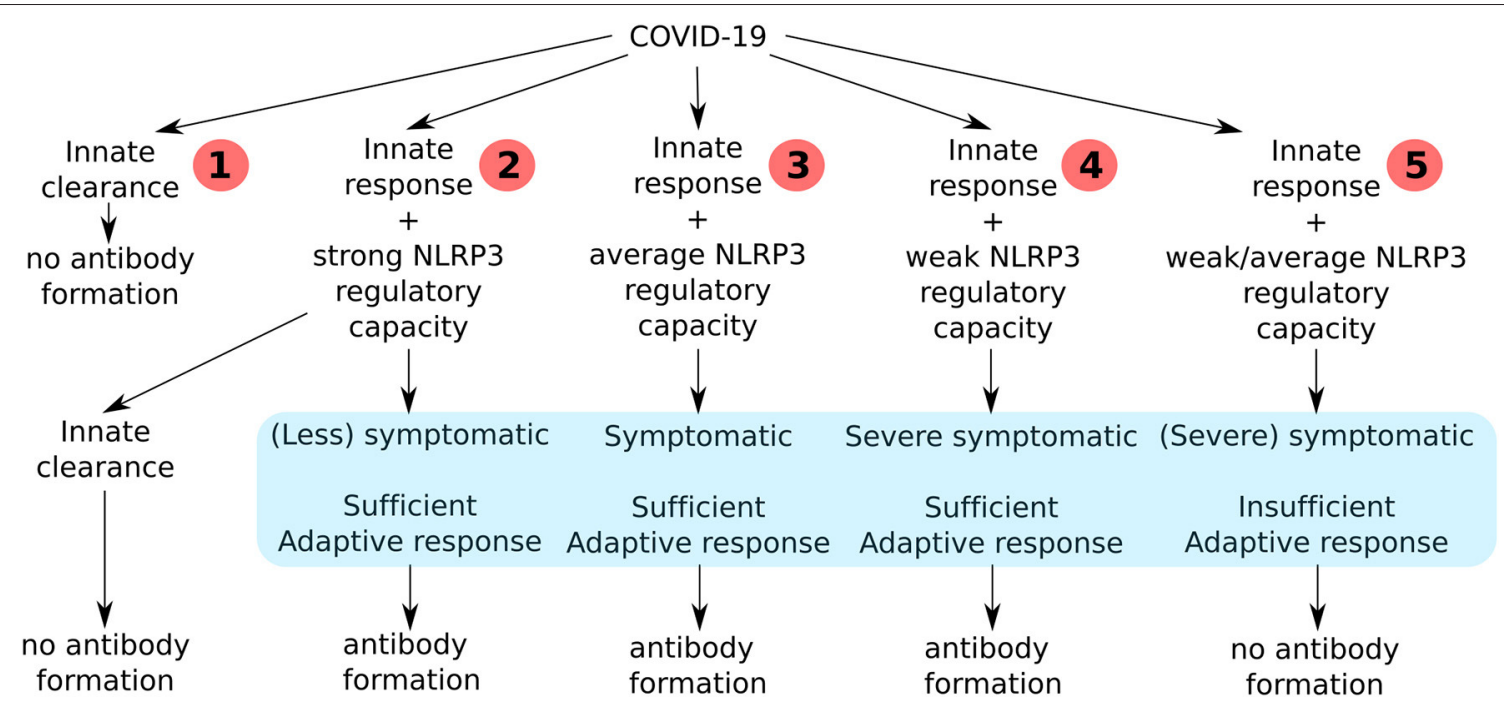

FIGURE 1 | An overview of all the consequences of the clinical course of COVID-19 infection in humans depending on their immune fitness state.

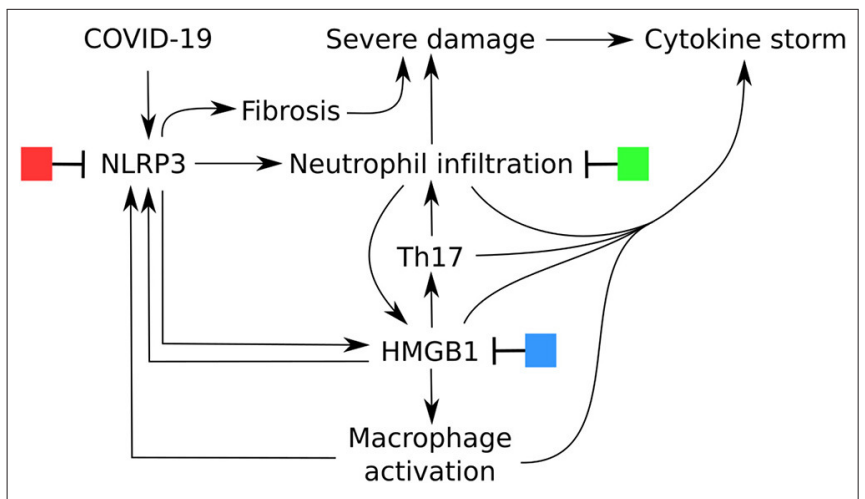

FIGURE 2 | Central role of NLRP3 inflammasome activation in the severe symptomatic phase of COVID-19 and potential options for treatment.

and IL1B (all $P<0.0001$ ) than female PBMC (23). Moreover, patients where the most lethality is observed are elderly and patients with non-communicable diseases and obesitas (1). Elderly patients having an "inflammaging," a low grade inflammation associated with NLRP3 inflammasome priming and activation and weaker inhibition (24) and, obese patients with a metainflammation (25) resulting in a higher base activity of NLRP3 $(26,27)$. An enhanced exposure to DAMPs and NLRP3 inflammasome activation can affect immune fitness and is the result of a complex interplay where genetics [SNPs in NLRP3 (28)] and also lifestyle factors [such as exercise, reduce NLRP3 activation (29), certain diets, block or stimulate NLRP3 activation $(30,31)$ and, air pollution, induces NLRP3 activation (32)] are interconnected.

In search for a pathway to relate sustained NLRP3 inflammasome activation in aging we found a microRNA that has Pyrin-only protein 1 (POP1) as its target (33). This miR-34-5p is found to be increased in skeletal muscle and in serum-derived extracellular vesicles in an experimental model and considered as an "inflammiR" (34). From these data it is tempting to speculate that age-increased miR-34-5p results in the diminished capacity to deactivate NLRP3 by inhibiting POP1 production.

Evidence is accumulating that one of the main downstream DAMPs of NLRP3 activation is HMGB1. HMGB1 was originally discovered to be involved in endotoxin lethality in mice (35). It is a critical late marker of sepsis (36) and infection responsible for epithelial barrier failure, organ dysfunction, vascular leakage and even death (37). In high levels HMGB1 is a central mediator of an excessive inflammatory response and severity of pathology during the course of viral infections $(7,38)$, but low levels mediate sickness behavior, antibacterial activities and might be beneficial when accelerating alveolar epithelial repair (39). Most of the evidence comes from experimental influenza virus models and acute lung injury where infection/injury induces increased HMGB1 levels in the lungs that contribute to the severity of pneumonia, correlate to death and can be blocked with HMGB1-specific antibody $(38,40)$. This increased HMGB1 is also responsible for neutrophil infiltration, regulated via IL17 (41). Taken together, overactive NLRP3 with neutrophil infiltration, Th17, HMGB1 and macrophage activation is likely to be the cause for the pathological findings and the cytokine storm in severe COVID-19 $(42,43)$, which is hyperstimulated by positive feedback loops (44).

\section{TREATMENT OPTIONS}

The discrimination into two phases of the clinical disease requires also the need for a dual treatment approach (2). In the first immune defense-based protective phase there is a need for therapies that reduce virus entry and help to eradicate the virus by boosting the immune system. In the second inflammation-driven damaging phase the endogenous adjuvant 
reaction of the immune system should be suppressed. In Figure 2 there are potential options for treatment depicted. For each of these options a large number of potential candidates are available. We will highlight some and refer to other authors that have summarized this. The first clinical study for a NLRP3 inflammasome inhibitor (Tranilast) to treat COVID-19 is ongoing and registered in the Chinese clinical trial registry (45). Other studies are still in a pre-clinical phase and study the effect on acute lung injury or on cell lines for example with resveratrol (46), tetracycline (47) or erythropoietin (48) or nicardipine, a L-type calcium antagonist (49), lidocaine (50) CP456,773 (51), Diacerein (52). For colchicine it is hypothesized that it has an effect on NLRP3-mediated diseases (53). In several reviews other NLRP3 inflammasome inhibitors are listed $(14,16,27,54)$.

A second potential target for treatment is HMGB1 (55). In experimental models of acute lung injury or sepsis blocking of HMGB1 or one of its receptors has shown a beneficial effect $(38,40,56,57)$. Even though the antiHMGB1 has no effect on the proliferation of the virus, in combination with peravimir a significant effect on neutrophil infiltration and macrophage aggregation was observed (57). Also Chloroquine (58), Methotrexate (59), anti-oxidants (60-62), traditional Chinese medicine $(63,64)$, thrombomodulin $(65)$, and others (66-68) are listed as potential therapeutic strategies to diminish HMGB1.

Another option to limit severe damage would be to reduce the number of neutrophils. Already in a phase II clinical trial for COVID-19 CM4620-IE is tested ${ }^{1}$ This is a calcium releaseactivated calcium CRAC channel inhibitor aiming to stabilize pulmonary endothelial capillary barrier, reduce neutrophil infiltration and prevent lung injury (69). Several candidates

\footnotetext{
${ }^{1}$ https://www.globenewswire.com/news-release/2020/04/09/2014265/0/en/FDAGrants-CalciMedica-Permission-to-Begin-Dosing-CM4620-IE-in-Patientswith-Severe-COVID-19-Pneumonia- under-a-Newly-Opened-IND.html
}

from pre-clinical work can be distinguished, Galactin-9 inhibits the infiltration of neutrophils and decreases MMP levels and moreover down-regulates Th1 and Th17 T cells (70) and exogenous carbon monoxide delivered from carbon monoxidereleasing molecule 2 inhibits neutrophil infiltration (71). This treatment also inhibited NLRP3 activation in vitro (72) and HMGB1 in an in vivo model (73) and a suggestion is made that this could also be of use in the current ICU (74).

Finally, also blocking the downstream mediators of NLRP3 inflammasome activation caspase- 1 and cytokines IL- $1 \beta$ and IL18 and their receptors are potential options for treatment for COVID-19-related pneumonia (75-77).

\section{FINAL REMARKS}

The data presented in this overview suggest that the NLRP3 inflammasome with its downstream pathways is an attractive target for therapy of COVID-19 with (severe) pathology in individuals that have a low immune fitness. Knowledge of early indications of possible scenarios after infection will be needed to be able to timely intervene with an appropriate therapy. Several potential candidates are available that are already or might be readily tested in clinical practice. For prevention early signaling of the presence of low grade inflammation might be an indicator for loss of resilience leading to vulnerability to a viral challenge. It also might be an incentive to implement lifestyle changes to enhance immune fitness.

\section{AUTHOR CONTRIBUTIONS}

DB: performed literature search, figures, data collection, data analysis, and data interpretation. AV: performed literature search, study design, data collection, data analysis, data interpretation, and writing. All authors contributed to the article and approved the submitted version.

\section{REFERENCES}

1. Guan WJ, Ni ZY, Hu Y, Liang WH, Ou CQ, He JX, et al. Clinical characteristics of coronavirus disease 2019 in China. N Engl J Med. (2020) 382:1708-20. doi: 10.1101/2020.02.06.20020974

2. Shi Y, Wang Y, Shao C, Huang J, Gan J, Huang X, et al. COVID-19 infection: the perspectives on immune responses. Cell Death Differ. (2020) 27:1451-4. doi: 10.1038/s41418-020-0530-3

3. Te Velde AA, Bezema T, van Kampen AH, Kraneveld AD, t Hart BA, van Middendorp $\mathrm{H}$, et al. Embracing complexity beyond systems medicine: a new approach to chronic immune disorders. Front Immunol. (2016) 7:587. doi: 10.3389/fimmu.2016.00587

4. Scheffer M, Bolhuis JE, Borsboom D, Buchman TG, Gijzel SMW, Goulson D, et al. Quantifying resilience of humans and other animals. Proc Natl Acad Sci USA. (2018) 115:11883-90. doi: 10.1073/pnas.1810630115

5. Zhou Y, He C, Wang L, Ge B. Post-translational regulation of antiviral innate signaling. Eur J Immunol. (2017) 47:1414-26. doi: 10.1002/eji.201746959

6. Ros U, Pedrera L, Garcia-Saez AJ. Partners in crime: the interplay of proteins and membranes in regulated necrosis. Int J Mol Sci. (2020) 21:2412. doi: $10.3390 /$ ijms 21072412

7. Wang H, Ward MF, Fan XG, Sama AE, Li W. Potential role of high mobility group box 1 in viral infectious diseases. Viral Immunol. (2006) 19:3-9. doi: $10.1089 /$ vim.2006.19.3

8. Chen IY, Moriyama M, Chang MF, Ichinohe T. Severe acute respiratory syndrome coronavirus viroporin 3a activates the NLRP3 inflammasome. Front Microbiol. (2019) 10:50. doi: 10.3389/fmicb.2019. 00050

9. Mousavizadeh L, Ghasemi S. Genotype and phenotype of COVID19: Their roles in pathogenesis. J Microbiol Immunol Infect. (2020). doi: 10.1016/j.jmii.2020.03.022. [Epub ahead of print].

10. Chan CM, Tsoi H, Chan WM, Zhai S, Wong CO, Yao X, et al. The ion channel activity of the SARS-coronavirus $3 \mathrm{a}$ protein is linked to its pro-apoptotic function. Int J Biochem Cell Biol. (2009) 41:2232-9. doi: 10.1016/j.biocel.2009.04.019

11. Ahn M, Anderson DE, Zhang Q, Tan CW, Lim BL, Luko K, et al. Dampened NLRP3-mediated inflammation in bats and implications for a special viral reservoir host. Nat Microbiol. (2019) 4:789-99. doi: 10.1038/s41564-019-0371-3

12. Shattuck EC, Muehlenbein MP. Human sickness behavior: ultimate and proximate explanations. Am J Phys Anthropol. (2015) 157:1-18. doi: 10.1002/ajpa.22698

13. Fulop T, Larbi A, Witkowski JM. Human inflammaging. Gerontology. (2019) 65:495-504. doi: 10.1159/000497375

14. Kelley N, Jeltema D, Duan Y, He Y. The NLRP3 inflammasome: an overview of mechanisms of activation and regulation. Int J Mol Sci. (2019) 20:3328. doi: 10.3390/ijms20133328 
15. Mortimer L, Moreau F, MacDonald JA, Chadee K. NLRP3 inflammasome inhibition is disrupted in a group of auto-inflammatory disease CAPS mutations. Nat Immunol. (2016) 17:1176-86. doi: 10.1038/ni.3538

16. Swanson KV, Deng M, Ting JP. The NLRP3 inflammasome: molecular activation and regulation to therapeutics. Nat Rev Immunol. (2019) 19:477-89. doi: 10.1038/s41577-019-0165-0

17. Indramohan $\mathrm{M}$, Stehlik $\mathrm{C}$, Dorfleutner $\mathrm{A}$. COPs and POPs patrol inflammasome activation. J Mol Biol. (2018) 430:153-73. doi: 10.1016/j.jmb.2017.10.004

18. Cao X. COVID-19: immunopathology and its implications for therapy. Nat Rev Immunol. (2020) 20:269-27. doi: 10.1038/s41577-020-0308-3

19. Fukumoto J, Fukumoto I, Parthasarathy PT, Cox R, Huynh B, Ramanathan GK, et al. NLRP3 deletion protects from hyperoxia-induced acute lung injury. Am J Physiol Cell Physiol. (2013) 305:C182-9. doi: 10.1152/ajpcell.00086.2013

20. Satoh T, Kambe N, Matsue H. NLRP3 activation induces ASC-dependent programmed necrotic cell death, which leads to neutrophilic inflammation. Cell Death Dis. (2013) 4:e644. doi: 10.1038/cddis.2013.169

21. Feng Y, Yang Q, Xu J, Qian G, Liu Y. Effects of HMGB1 on PMN apoptosis during LPS-induced acute lung injury. Exp Mol Pathol. (2008) 85:214-22. doi: 10.1016/j.yexmp.2008.09.002

22. Potey PM, Rossi AG, Lucas CD, Dorward DA. Neutrophils in the initiation and resolution of acute pulmonary inflammation: understanding biological function and therapeutic potential. J Pathol. (2019) 247:672-85. doi: 10.1002/path.5221

23. Wu X, Cakmak S, Wortmann M, Hakimi M, Zhang J, Bockler D, et al. Sexand disease-specific inflammasome signatures in circulating blood leukocytes of patients with abdominal aortic aneurysm. Mol Med. (2016) 22:505-18. doi: 10.2119/molmed.2016.00035

24. Latz E, Duewell P. NLRP3 inflammasome activation in inflammaging. Semin Immunol. (2018) 40:61-73. doi: 10.1016/j.smim.2018.09.001

25. Christ A, Latz E. The Western lifestyle has lasting effects on metaflammation. Nat Rev Immunol. (2019) 19:267-8. doi: 10.1038/s41577-019-0156-1

26. Rheinheimer J, de Souza BM, Cardoso NS, Bauer AC, Crispim D. Current role of the NLRP3 inflammasome on obesity and insulin resistance: A systematic review. Metabolism. (2017) 74:1-9. doi: 10.1016/j.metabol.2017.06.002

27. Baldwin AG, Brough D, Freeman S. Inhibiting the inflammasome: a chemical perspective. J Med Chem. (2016) 59:1691-710. doi: 10.1021/acs.jmedchem.5b01091

28. Verma D, Lerm M, Blomgran Julinder R, Eriksson P, Soderkvist P, Sarndahl E. Gene polymorphisms in the NALP3 inflammasome are associated with interleukin-1 production and severe inflammation: relation to common inflammatory diseases? Arthritis Rheum. (2008) 58:888-94. doi: 10.1002/art.23286

29. Lee J, Lee Y, LaVoy EC, Umetani M, Hong J, Park Y. Physical activity protects NLRP3 inflammasome-associated coronary vascular dysfunction in obese mice. Physiol Rep. (2018) 6:e13738. doi: 10.14814/phy2.13738

30. Youm YH, Nguyen KY, Grant RW, Goldberg EL, Bodogai M, Kim $\mathrm{D}$, et al. The ketone metabolite beta-hydroxybutyrate blocks NLRP3 inflammasome-mediated inflammatory disease. Nat Med. (2015) 21:263-9. doi: $10.1038 / \mathrm{nm} .3804$

31. Christ A, Gunther P, Lauterbach MAR, Duewell P, Biswas D, Pelka K, et al. Western diet triggers NLRP3-dependent innate immune reprogramming. Cell. (2018) 172:162-75. e14. doi: 10.1016/j.cell.2017.12.013

32. Zheng R, Tao L, Jian H, Chang Y, Cheng Y, Feng Y, et al. NLRP3 inflammasome activation and lung fibrosis caused by airborne fine particulate matter. Ecotoxicol Environ Saf. (2018) 163:612-9. doi: 10.1016/j.ecoenv.2018.07.076

33. Hart M, Walch-Ruckheim B, Krammes L, Kehl T, Rheinheimer S, Tanzer T, et al. miR-34a as hub of $\mathrm{T}$ cell regulation networks. J Immunother Cancer. (2019) 7:187. doi: 10.1186/s40425-019-0670-5

34. Fulzele S, Mendhe B, Khayrullin A, Johnson M, Kaiser H, Liu Y, et al. Musclederived miR-34a increases with age in circulating extracellular vesicles and induces senescence of bone marrow stem cells. Aging. (2019) 11:1791-803. doi: 10.18632/aging.101874

35. Wang H, Bloom O, Zhang M, Vishnubhakat JM, Ombrellino M, Che J, et al. HMG-1 as a late mediator of endotoxin lethality in mice. Science. (1999) 285:248-51. doi: 10.1126/science.285.5425.248

36. Wang H, Yang H, Czura CJ, Sama AE, Tracey KJ. HMGB1 as a late mediator of lethal systemic inflammation. Am J Respir
Crit Care Med. (2001) 164:1768-73. doi: 10.1164/ajrccm.164.10.21 06117

37. Andersson U, Tracey KJ. HMGB1 is a therapeutic target for sterile inflammation and infection. Annu Rev Immunol. (2011) 29:139-62. doi: 10.1146/annurev-immunol-030409-101323

38. Hou XQ, Qin JL, Zheng XX, Wang L, Yang ST, Gao YW, et al. Potential role of high-mobility group box 1 protein in the pathogenesis of influenza H5N1 virus infection. Acta Virol. (2014) 58:69-75. doi: 10.4149/av_2014_01_69

39. Pittet JF, Koh H, Fang X, Iles K, Christiaans S, Anjun N, et al. HMGB1 accelerates alveolar epithelial repair via an IL-1beta- and alphavbeta6 integrin-dependent activation of TGF-betal. PLoS ONE. (2013) 8:e63907. doi: 10.1371/journal.pone.0063907

40. Nosaka N, Yashiro M, Yamada M, Fujii Y, Tsukahara H, Liu K, et al. Anti-high mobility group box-1 monoclonal antibody treatment provides protection against influenza A virus (H1N1)-induced pneumonia in mice. Crit Care. (2015) 19:249. doi: 10.1186/s13054-015-0983-9

41. Yan B, Chen F, Xu L, Xing J, Wang X. HMGB1-TLR4-IL23-IL17A axis promotes paraquat-induced acute lung injury by mediating neutrophil infiltration in mice. Sci Rep. (2017) 7:597. doi: 10.1038/s41598-017-00721-8

42. Xu Z, Shi L, Wang Y, Zhang J, Huang L, Zhang C, et al. Pathological findings of COVID-19 associated with acute respiratory distress syndrome. Lancet Respir Med. (2020) 8:420-2. doi: 10.1016/S2213-2600(20)30076-X

43. Wu D, Yang XO. TH17 responses in cytokine storm of COVID-19: An emerging target of JAK2 inhibitor fedratinib. J Microbiol Immunol Infect. (2020) 53:368-70. doi: 10.1016/j.jmii.2020.03.005

44. Kim EJ, Park SY, Baek SE, Jang MA, Lee WS, Bae SS, et al. HMGB1 increases IL-1beta production in vascular smooth muscle cells via NLRP3 inflammasome. Front Physiol. (2018) 9:313. doi: 10.3389/fphys.2018.00313

45. Huang Y, Jiang H, Chen Y, Wang X, Yang Y, Tao J, et al. Tranilast directly targets NLRP3 to treat inflammasome-driven diseases. EMBO Mol Med. (2018) 10:e8689. doi: 10.15252/emmm.201708689

46. Chang YP, Ka SM, Hsu WH, Chen A, Chao LK, Lin CC, et al. Resveratrol inhibits NLRP3 inflammasome activation by preserving mitochondrial integrity and augmenting autophagy. J Cell Physiol. (2015) 230:1567-79. doi: $10.1002 /$ jcp. 24903

47. Bode C, Peukert K, Schewe J-C, Putensen C, Latz E, Steinhagen F. Tetracycline alleviates acute lung injury by inhibition of NLRP3 inflammasome. Euro Respir J. (2019) 54(Suppl. 63):PA2175. doi: 10.1183/13993003.congress-2019.PA2175

48. Cao F, Tian X, Li Z, Lv Y, Han J, Zhuang R, et al. Suppression of NLRP3 inflammasome by erythropoietin via the EPOR/JAK2/STAT3 pathway contributes to attenuation of acute lung injury in mice. Front Pharmacol. (2020) 11:306. doi: 10.3389/fphar.2020.00306

49. Chang YY, Jean WH, Lu CW, Shieh JS, Chen ML, Lin TY. Nicardipine inhibits priming of the NLRP3 inflammasome via suppressing LPS-induced TLR4 expression. Inflammation. (2020). doi: 10.1007/s10753-020-01215-y. [Epub ahead of print].

50. Yang X, Yang LX, Wu J, Guo ML, Zhang Y, Ma SG. Treatment of lidocaine on subacute thyroiditis via restraining inflammatory factor expression and inhibiting pyroptosis pathway. J Cell Biochem. (2019) 120:10964-71. doi: $10.1002 /$ jcb. 27675

51. Primiano MJ, Lefker BA, Bowman MR, Bree AG, Hubeau C, Bonin PD, et al. Efficacy and pharmacology of the NLRP3 inflammasome inhibitor CP456,773 (CRID3) in murine models of dermal and pulmonary inflammation. J Immunol. (2016) 197:2421-33. doi: 10.4049/jimmunol.1600035

52. Fouad AA, Abdel-Aziz AM, Hamouda AAH. Diacerein downregulates NLRP3/caspase-1/IL-1beta and IL-6/STAT3 pathways of inflammation and apoptosis in a rat model of cadmium testicular toxicity. Biol Trace Elem Res. (2020) 195:499-505. doi: 10.1007/s12011-019-01865-6

53. Demidowich AP, Davis AI, Dedhia N, Yanovski JA. Colchicine to decrease NLRP3-activated inflammation and improve obesityrelated metabolic dysregulation. Med Hypotheses. (2016) 92:67-73. doi: 10.1016/j.mehy.2016.04.039

54. Shao BZ, Xu ZQ, Han BZ, Su DF, Liu C. NLRP3 inflammasome and its inhibitors: a review. Front Pharmacol. (2015) 6:262. doi: 10.3389/fphar.2015.00262

55. Chen G, Chen DZ, Li J, Czura CJ, Tracey KJ, Sama $\mathrm{AE}$, et al. Pathogenic role of HMGB1 in SARS? Med 
Hypotheses. (2004) 63:691-5. doi: 10.1016/j.mehy.2004. 01.037

56. Patel MC, Shirey KA, Boukhvalova MS, Vogel SN, Blanco JCG. Serum high-mobility-group box 1 as a biomarker and a therapeutic target during respiratory virus infections. mBio. (2018) 9:e00246-18. doi: $10.1128 / \mathrm{mBio} .00246-18$

57. Hatayama K, Nosaka N, Yamada M, Yashiro M, Fujii Y, Tsukahara H, et al. Combined effect of anti-high-mobility group box-1 monoclonal antibody and peramivir against influenza A virus-induced pneumonia in mice. J Med Virol. (2019) 91:361-9. doi: 10.1002/jmv.25330

58. Yang M, Cao L, Xie M, Yu Y, Kang R, Yang L, et al. Chloroquine inhibits HMGB1 inflammatory signaling and protects mice from lethal sepsis. Biochem Pharmacol. (2013) 86:410-8. doi: 10.1016/j.bcp.2013. 05.013

59. Bedoui Y, Guillot X, Selambarom J, Guiraud P, Giry C, Jaffar-Bandjee MC, et al. Methotrexate an old drug with new tricks. Int J Mol Sci. (2019) 20:5023. doi: 10.3390/ijms20205023

60. Entezari M, Javdan M, Antoine DJ, Morrow DM, Sitapara RA, Patel $\mathrm{V}$, et al. Inhibition of extracellular HMGB1 attenuates hyperoxiainduced inflammatory acute lung injury. Redox Biol. (2014) 2:314-22. doi: 10.1016/j.redox.2014.01.013

61. Patel V, Dial K, Wu J, Gauthier AG, Wu W, Lin M, et al. Dietary antioxidants significantly attenuate hyperoxia-induced acute inflammatory lung injury by enhancing macrophage function via reducing the accumulation of airway HMGB1. Int J Mol Sci. (2020) 21:977. doi: 10.3390/ijms210 30977

62. Zhang $\mathrm{R}$, Wang $\mathrm{X}$, Ni L, Di X, Ma B, Niu S, et al. COVID-19: melatonin as a potential adjuvant treatment. Life Sci. (2020) 250:117583. doi: 10.1016/j.lfs.2020.117583

63. Ding J, Cui X, Liu Q. Emerging role of HMGB1 in lung diseases: friend or foe. J Cell Mol Med. (2017) 21:1046-57. doi: 10.1111/jcmm. 13048

64. Fei YX, Zhao B, Yin QY, Qiu YY, Ren GH, Wang BW, et al. Ma xing shi gan decoction attenuates PM2.5 induced lung injury via inhibiting HMGB1/TLR4/NFkappaB signal pathway in rat. Front Pharmacol. (2019) 10:1361. doi: 10.3389/fphar.2019.01361

65. Kudo D, Toyama M, Aoyagi T, Akahori Y, Yamamoto H, Ishii K, et al. Involvement of high mobility group box 1 and the therapeutic effect of recombinant thrombomodulin in a mouse model of severe acute respiratory distress syndrome. Clin Exp Immunol. (2013) 173:276-87. doi: $10.1111 /$ cei.12106

66. Andersson U, Yang H, Harris H. Extracellular HMGB1 as a therapeutic target in inflammatory diseases. Expert Opin Ther Targets. (2018) 22:263-77. doi: 10.1080/14728222.2018.1439924

67. Lee SA, Kwak MS, Kim S, Shin JS. The role of high mobility group box 1 in innate immunity. Yonsei Med J. (2014) 55:1165-76. doi: 10.3349/ymj.2014.55.5.1165

68. Andersson U, Ottestad W, Tracey KJ. Extracellular HMGB1: a therapeutic target in severe pulmonary inflammation including
COVID-19? Mol Med. (2020) 26:42. doi: 10.1186/s10020-020-00 $172-4$

69. Immler R, Simon SI, Sperandio M. Calcium signalling and related ion channels in neutrophil recruitment and function. Eur J Clin Invest. (2018) 48(Suppl. 2):e12964. doi: 10.1111/eci.12964

70. Horio Y, Ichiyasu H, Kojima K, Saita N, Migiyama Y, Iriki T, et al. Protective effect of Galectin-9 in murine model of lung emphysema: Involvement of neutrophil migration and MMP-9 production. PLoS ONE. (2017) 12:e0180742. doi: 10.1371/journal.pone.0180742

71. Wang X, Qin W, Song M, Zhang Y, Sun B. Exogenous carbon monoxide inhibits neutrophil infiltration in LPS-induced sepsis by interfering with FPR1 via p38 MAPK but not GRK2. Oncotarget. (2016) 7:34250-65. doi: 10.18632/oncotarget.9084

72. Jung SS, Moon JS, Xu JF, Ifedigbo E, Ryter SW, Choi AM, et al. Carbon monoxide negatively regulates NLRP3 inflammasome activation in macrophages. Am J Physiol Lung Cell Mol Physiol. (2015) 308:L1058-67. doi: 10.1152/ajplung.00400.2014

73. Jia Y, Wang L, Zhao GY, Wang ZQ, Chen S, Chen G. Carbon monoxide inhibits the nuclear-cytoplasmic translocation of HMGB1 in an in vitro oxidative stress injury model of mouse renal tubular epithelial cells. J Huazhong Univ Sci Technol Med Sci. (2016) 36:791-5. doi: 10.1007/s11596-016-1663-y

74. Goebel U, Wollborn J. Carbon monoxide in intensive care medicine-time to start the therapeutic application?! Intensive Care Med Exp. (2020). 8:2. doi: 10.1186/s40635-020-0292-8

75. Pontali E, Volpi S, Antonucci G, Castellaneta M, Buzzi D, Tricerri F, et al. Safety and efficacy of early high-dose IV anakinra in severe COVID-19 lung disease. J Allergy Clin Immunol. (2020). doi: 10.1016/j.jaci.2020.05.002. [Epub ahead of print].

76. Jamilloux Y, Henry T, Belot A, Viel S, Fauter M, El Jammal T, et al. Should we stimulate or suppress immune responses in COVID-19? Cytokine and anti-cytokine interventions. Autoimmun Rev. (2020) 19:102567. doi: 10.1016/j.autrev.2020.102567

77. Soy M, Keser G, Atagunduz P, Tabak F, Atagunduz I, Kayhan S. Cytokine storm in COVID-19: pathogenesis and overview of antiinflammatory agents used in treatment. Clin Rheumatol. (2020) 39:2085-94. doi: 10.1007/s10067-020-05190-5

Conflict of Interest: The authors declare that the research was conducted in the absence of any commercial or financial relationships that could be construed as a potential conflict of interest.

Copyright (c) 2020 van den Berg and te Velde. This is an open-access article distributed under the terms of the Creative Commons Attribution License (CC BY). The use, distribution or reproduction in other forums is permitted, provided the original author(s) and the copyright owner(s) are credited and that the original publication in this journal is cited, in accordance with accepted academic practice. No use, distribution or reproduction is permitted which does not comply with these terms. 